\title{
Configurações
}

Revista Ciências Sociais

$27 \mid 2021$

Vária

\section{Perfis de envolvimento cívico e político juvenil nas redes sociais: explorando atitudes e comportamentos}

Profiles of youth civic and political participation in social media: exploring attitudes and behaviours

Profils d'engagement civique et politique des jeunes dans les médias sociaux:

une exploration des attitudes et des comportements

Ricardo Soares, Pedro Ferreira e Carla Malafaia

\section{CpenEdition}

Journals

\section{Edição electrónica}

URL: https://journals.openedition.org/configuracoes/11850

DOI: $10.4000 /$ configuracoes. 11850

ISSN: 2182-7419

\section{Editora}

Centro de Investigação em Ciências Sociais

Edição impressa

Paginação: 39-55

ISSN: 1646-5075

\section{Refêrencia eletrónica}

Ricardo Soares, Pedro Ferreira e Carla Malafaia, «Perfis de envolvimento cívico e político juvenil nas redes sociais: explorando atitudes e comportamentos», Configurações [Online], 27 | 2021, posto online no dia 24 junho 2021, consultado o 26 junho 2021. URL: http://journals.openedition.org/ configuracoes/11850 ; DOI: https://doi.org/10.4000/configuracoes. 11850 
Soares, Ricardo; Ferreira, Pedro; Malafaia, Carla - Perfis de envolvimento cívico e político juvenil nas redes sociais: explorando atitudes e comportamentos. Configurações, vol. 27, 2021, pp. 39-55.

\title{
Perfis de envolvimento cívico e político juvenil nas redes sociais: explorando atitudes e comportamentos
}

\author{
RICARDO SOARES* \\ Faculdade de Psicologia e Ciências da Educação da Universidade do Porto \\ PEDRO FERREIRA** \\ Centro de Investigação e Intervenção Educativas (CIIE) - Faculdade de Psicologia e Ciências da Educação da \\ Universidade do Porto \\ CARLA MALAFAIA*** \\ Centro de Investigação e Intervenção Educativas (CIIE) - Faculdade de Psicologia e Ciências da Educação da \\ Universidade do Porto
}

\begin{abstract}
Resumo
Considerando o potencial das redes sociais como contex tos de participação, este artigo visa compreender modos de envolvimento cívico e político juvenil nestas plataformas. Para tal recorremos a uma metodologia sequencial mista, contemplando inquéritos por questionário e grupos de discussão com jovens estudantes.

Dos dados quantitativos emergiram quatro perfis de envolvimento político online que incluem dimensões comportamentais e atitudinais: participativos; desinteressados; esperançosos; confiantes. A exploração qualitativa destes perfis permite problematizá-los, mostrando que as redes sociais são um espaço relevante de participação e importante na mobilização, apesar de também acomodarem estilos de envolvimento pouco comprometido.
\end{abstract}

Palavras-chave: jovens, métodos mistos, participação cívica e política, redes sociais.

\footnotetext{
Abstract

Profiles of youth civic and political participation in social media: exploring attitudes and behaviours

Considering the potential of social media as contexts for participation, this article aims to understand the modes of youth civic and political engagement on these platforms. For this, we used a sequential mixed-methods approach, encompassing questionnaires and focus group discussions with young students.

Four profiles of online political participation that include behavioural and attitudinal dimensions emerged from the quantitative data: "participative", "disinterested",

*E-mail: ricardosoaresfpceup @gmail.com | ORCID ID: https://orcid.org/0000-0002-1955-7832

**E-mail: pferreira @fpce.up.pt | ORCID ID: https://orcid.org/0000-0002-5010-7397

***E-mail: carlamalafaia@fpce.up.pt | ORCID ID: https://orcid.org/0000-0001-5490-1187
} 
"hopeful", and "confident". The qualitative exploration of these profiles allows their problematisation, showing that social media is a relevant sphere for participation and important for the mobilisation processes, even though it also accommodates low commitment styles of engagement.

Keywords: youth, mixed-methods, civic and political participation, social media.

\begin{abstract}
Resumé
Profils d'engagement civique et politique des jeunes dans les médias sociaux : une exploration des attitudes et des comportements

Considérant le potentiel des médias sociaux comme contextes de participation, cet article vise à comprendre les modes d'engagement civique et politique des jeunes sur ces plateformes. Pour cela, nous avons utilisé une approche séquentielle de méthodes mixtes, comprenant des questionnaires et des discussions de groupe avec de jeunes étudiants.

Quatre profils d'implication politique en ligne, qui incluent des dimensions comportementales et attitudinales, ont émergé des données quantitatives : «participatifs », « désintéressés », « optimistes » et « confiants ». L'exploration qualitative de ces profils permet de les problématiser, en montrant que les médias sociaux sont une sphère de participation et mobilisation pertinente, même s'ils accueillent également des styles d'engagements faibles.
\end{abstract}

Mots-clés: jeunes, méthodes mixtes, participation civique et politique, médias sociaux.

\title{
Introdução
}

As redes sociais online (RS) são, atualmente, espaços digitais incontornáveis de sociabilidade juvenil e construção de cidadania (e.g., Hodgin, 2019; Kahne e Bowyer, 2019). Esta investigação ancora-se na necessidade de compreender as atitudes e os comportamentos cívicos e políticos juvenis que decorrem de práticas digitais, nomeadamente em RS. Este artigo visa dar conta de atitudes e comportamentos cívicos e políticos juvenis nas RS e, assim, compreender o papel que estas plataformas digitais têm, ou podem ter, no envolvimento político dos jovens.

Desde já, importa sublinhar que se usará o termo “participação cívica e política" (PCP), na medida em que se pretende dar conta da abrangência dos modos de participação, reconhecendo que o "cívico" e o "político" são dimensões que podem relacionar-se e até sobrepor-se (e.g., Van Deth, 2014), mas que podem também refletir práticas de participação e conceções de mudança social radicalmente distintas (Malafaia et al., 2017). 
A primeira secção do artigo procura detalhar o quadro teórico que subjaz ao desenvolvimento desta investigação, nomeadamente no que diz respeito à PCP juvenil e à crescente relevância que as RS têm adquirido nas práticas de cidadania. Seguidamente, apresentamos o desenho metodológico da investigação que combina inquéritos por questionário com grupos de discussão focalizada. $\mathrm{Na}$ terceira secção apresentamos a análise dos dados relativos às duas fases empíricas que compõem a investigação. Os dados quantitativos e os dados qualitativos são apresentados conjuntamente, de modo a promover uma leitura integrada do fenómeno em estudo, explorando-se o uso das RS como estratégia de participação, bem como o papel que estas plataformas digitais têm, ou podem ter, no envolvimento político juvenil. Finaliza-se o artigo com a discussão dos principais resultados da investigação.

\section{Login: jovens, participação cívica e política e redes sociais}

A prevalência de sistemas e tecnologias digitais nos quotidianos juvenis tem estimulado o interesse académico sobre a relação entre as práticas digitais e os níveis de PCP.

Segundo Bennett (2008), existe uma visão dicotómica sobre a participação juvenil. Por um lado, a retórica do desengajamento juvenil que aponta o declínio na relação com formas mais tradicionais de envolvimento e que retrata os jovens como apáticos, apolíticos e desinteressados (e.g., Sander e Putnam, 2010). Por outro lado, o reconhecimento de que os jovens são atores políticos comprometidos, críticos e interessados (e.g., Magalhães e Moral, 2008; Malafaia, Menezes e Neves, 2016), que protagonizam a 'reinvenção do ativismo político' (Norris, 2002), dado participarem de formas novas e menos institucionalizadas (e.g., Benedicto, 2013; Pickard e Bessant, 2018). Com efeito, os jovens parecem envolver-se de modos mais criativos, fluidos, informais e horizontais (Benedicto, 2013; Farthing, 2010). A este respeito, Loader, Vromen e Xenos (2014) caracterizam a geração juvenil como networked young citizen, dada a sua propensão para o envolvimento em redes mais horizontais e a adoção de um modelo de cidadania fluido, reflexivo e em (auto)atualização - fortemente ancorado nos novos media digitais -, que rompe com os ideais convencionais de um dutiful citizen (Bennett, 2008). Do mesmo modo, Pickard (2019) assinala que os jovens adotam práticas participativas não eleitorais, criativas, autónomas e ligadas às RS - participação DIO (Do-it-Ourselves) -, de acordo com objetivos e causas concretas.

Nesta linha, alguns autores sublinham que os jovens tomam vantagem da hibridez e interatividade da esfera online (e.g., Campos e Simões, 2014) para exercerem a sua agência, influência e voz relativamente a questões políticas, assumindo os media digitais como contex tos de política participatória (Kahne, 
Middaugh e Allen, 2015; Soep, 2014). Importa lembrar, a este respeito, os movimentos sociais que tomaram as ruas em distintos pontos do planeta, no início do milénio - a Primavera Árabe, o movimento O ccupy, as manifestações anti-austeridade, etc. -, alicerçados significativamente na esfera digital (e.g., Castells, 2012).

As RS surgem como um contexto primordial de envolvimento político, com implicações em termos de cultura participatória (Jenkins et al., 2009), uma vez que os utilizadores circulam, criam e consomem conteúdo e conectam com um grande número de pessoas que também partilham os seus interesses (Kahne e Bowyer, 2019). De facto, considera-se que estas plataformas vieram conduzir a uma reconfiguração do social e do político nas sociedades contemporâneas (e.g., Cardoso et al., 2015), dada a possibilidade de representarem um instrumento útil na mudança social, quer sejam usadas para protestar, quer, simplesmente, para acompanhar acontecimentos políticos e sociais (Cardoso, 2011; Simões e Campos, 2016). Como afirmam Campos, Pereira e Simões (2016), as RS marcam um paradigma e um período historicamente distinto de ativismo, promovendo e estimulando novas possibilidades políticas de envolvimento democrático e colaboração em massa (e.g., Zuckerman, 2014).

As RS parecem servir para divulgar mensagens, reunir seguidores, organizar protestos, avançar com contestações e apresentar reivindicações (e.g., Mihailidis, 2014). A este respeito, a investigação mostra a relação positiva do uso das RS com a confiança social e o envolvimento cívico e político (Loader et al., 2014; Valenzuela, Park e Kee, 2009), sendo que a discussão de assuntos políticos nas RS parece estimular o comprometimento político juvenil (Zhang et al., 2009).

No polo oposto, critica-se o baixo nível de comprometimento da participação online (Livingstone, 2011). Fenómenos como o 'slacktivism' questionam precisamente a natureza das formas de participação online e o modo como a eficácia das ações se relaciona mais com o bem-estar dos participantes do que com objetivos de transformação social e política, além de se tratar de modos de envolvimento que não correspondem a comportamentos políticos fora da esfera online (e.g., Morozov, 2011). Ou seja, considera-se o "ativismo de sofá ou do like (...) como uma prática comodista e pouco implicada de fazer ativismo" (Campos et al., 2016: 41).

Ademais, questionam-se as potencialidades de empoderamento dos meios digitais, dado que apenas uma minoria os utiliza para participar ou se envolver civicamente (Buckingham, 2008; Kotilainen, 2009). Também Bennett (2008) e Baumgartner e Morris (2009) sublinham que a população juvenil tende a desenvolver atividades online mais voltadas para dimensões sociais e de entretenimento do que para o mundo da política. Do mesmo modo, Boyd (2008) refere que os utilizadores das RS estão mais dedicados a adicionar brilho às suas páginas do que a engajar-se em qualquer forma de ação cívica coletiva. 


\section{0 perfil metodológico do estudo}

A literatura neste campo evidencia o papel incontornável das redes sociais na participação democrática contemporânea: com potencialidades e riscos para o modo como os jovens se relacionam com questões cívicas e políticas. Assim, este artigo procura contribuir para a compreensão das atitudes e dos comportamentos cívicos e políticos online dos jovens, procurando explorar o papel das RS como contex tos emergentes de PCP.

Para isto, adotou-se um desenho metodológico sequencial misto (Creswell, 2014) assente em dois níveis de análise: um primeiro individual e um subsequente grupal. Esta opção permite que as informações e resultados da análise precedente informem e esclareçam o passo seguinte, numa investigação articulada, coerente e interdependente. $\mathrm{Na}$ prática, utilizou-se um inquérito por questionário para mapear atitudes e comportamentos cívicos e políticos dos jovens e realizaram-se grupos de discussão focalizada (GDF) para discutir os resultados quantitativos, tendo em conta o papel que as RS podem ter no envolvimento político juvenil.

A recolha de dados realizou-se numa escola pública da região litoral norte de Portugal que apresentava uma oferta educativa, quer de ensino regular, quer de ensino profissional, e abrangia uma vasta zona geográfica, apresentando uma população numerosa e bastante diversificada.

\subsection{A selfie quantitativa: amostra, instrumento e procedimento}

Numa primeira fase, foram administrados inquéritos por questionário a 392 jovens estudantes de 15 turmas do $9 .^{\circ}$ ao $12 .^{\circ}$ ano de escolaridade, quer do ensino regular (12), quer do ensino profissional (3) (quadro 1), sendo que 52,8\% são do sexo feminino e 47,2\% do sexo masculino. As idades variam entre 13 e 19 anos $\left(\mathrm{M}_{\text {idade }}=15.72, \mathrm{DP}=1.34\right)$. Quando questionados sobre o rendimento disponível na sua família, estes posicionaram-se, sobretudo, nas afirmações "dá para viver, assegurando as necessidadesfundamentais" (33,6\%) e "dáparaviverconfortavelmente" (64,6\%). De realçar que apenas 1,8\% dos inquiridos responde que o rendimento "mal dá para pagar as contas" e que nenhum afirma que o rendimento "não chega para pagar as despesas familiares". No que respeita ao número de livros em casa, verifica-se uma heterogeneidade da amostra ( $\mathrm{M}_{0-10}$ livros $\left.=16,6 \% ; M_{11-50 \text { livros }}=30,1 \% ; M_{51-100 ~ l i v r o s}=23,7 \% ; M_{\text {mais de } 101 \text { livros }}=29,6 \%\right)^{1}$.

1 As questões do rendimento familiar e do número de livros em casa foram usadas como indicadores do capital económico e capital cultural, à semelhança de estudos anteriores que as referem como variáveis proxy do estatuto socioeconómico (e.g., Lopes, Benton e Cleaver, 2009). 
Quadro 1. Composição da amostra da primeira fase do estudo (ano escolaridade, sexo, via de ensino a frequentar)

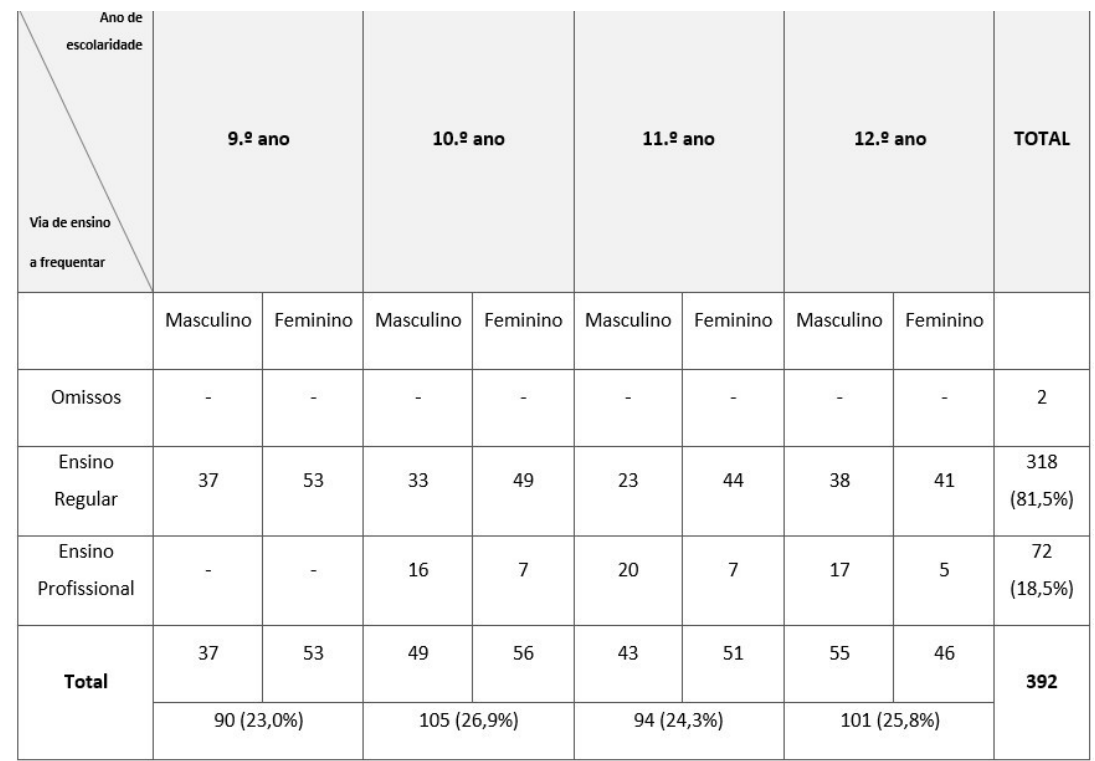

Nesta etapa, pretendeu-se observar os níveis de PCP nas RS, procurando explorar o modo como os jovens da nossa amostra se encontram agrupados por perfis de envolvimento, contemplando atitudes e comportamentos cívicos e políticos nas RS. Em linha com uma perspetiva multidimensional sobre a participação, consideramos importante não apenas explorar a dimensão comportamental do envolvimento cívico e político, mas reconhecer também as suas dimensões cognitivas e emocionais (Barrett e Zani, 2015; Menezes et al., 2012). Por exemplo, manifestar interesse e atenção por assuntos políticos, ou avaliar positivamente o poder (individual ou coletivo) para influenciar a mudança social, são dimensões centrais nos estudos de participação, por serem variáveis atitudinais que predizem comportamentos cívicos e políticos (e.g., Ekman e Amnå, 2012).

$\mathrm{Na}$ construção do questionário, e de modo a explorar comportamentos cívicos e políticos nos últimos 12 meses, adaptou-se a versão portuguesa da escala de ação política (Lyons, 2008; Menezes et al., 2012) com um total de 10 itens (e.g., "apoiar uma causa política, social ou ambiental através de um like ou comentário"; "participar num a reunião pública ou manifestação relacionada com questões sociais e políticas"). As opções de resposta à pergunta "Fiz esta atividade nos últimos 12 meses" variam de 1 (nunca) até 5 (muito frequentemente). 
A partir de uma análise fatorial exploratória desta escala, foi possível verificar a existência do constructo relativo à participação cívica e política nas redes sociais online [Alpha de Cronbach = .77], composta pelos itens: "apelar, através das redes sociais, à participação num a manifestação ou evento político elou social"; "visitar perfis de redes sociais com conteúdo relacionado com direitos humanos, LGBT ou ambientais"; "partilhar nas redes sociais notícias, músicas, fotografias ou vídeos com conteúdo social e político"; e "apoiar um a causa política, social ou ambiental através de um like ou comentário".

No que concerne às atitudes cívicas e políticas, explorámos o interesse e a eficácia política através de duas subescalas (e.g., Emler, 2011; Niemi, Craig e Mattei, 1991), com um total de nove itens (com respostas a variar entre 1, discordo totalmente, e 5, concordo totalmente). A partir de uma análise fatorial exploratória destas escalas resultaram: o interesse político [Alpha de Cronbach $=.84$ ] (e.g., "converso sobre questões sociais e políticas com os/as meus/minhas amigos/as e conhecidos/as"; "trago assuntos socais e políticos para a conversa com outras pessoas"; "tenho interesse na política”); a eficácia política interna [Alpha de Cronbach = .84] (e.g., "sei mais de política do que a maioria das pessoas da minha idade"; "quando estão a ser discutidos assuntos políticos, normalmente tenho algo a dizer”); e a eficácia política coletiva [Alpha de Cronbach = .75] (e.g., "as coisas podem mudar para melhorar se os jovens trabalharem em conjunto"; "se os jovens trabalharem em conjunto podem influenciar as decisões do governo").

$\mathrm{O}$ instrumento foi administrado em contex to de sala de aula, após assegurado o consentimento dos jovens participantes e dos encarregados de educação. Esta etapa decorreu entre novembro e dezembro de 2019.

\subsection{0 chat qualitativo: guião, participantes e procedimento}

Numa segunda fase, foram realizados quatro GDF com o objetivo de compreender como os jovens problematizam o papel das RS no envolvimento cívico e político juvenil.

Estes grupos foram conduzidos tendo por base um guião orientador. $\mathrm{Na}$ medida em que esta fase qualitativa teve um papel de complementaridade e expansão da fase antecedente do estudo, os tópicos de discussão foram elaborados tendo em conta os resultados preliminares da análise quantitativa. Estes resultados serviram de introdução a cada ponto de discussão, orientada para a relação entre a PCP juvenil e as RS. O objetivo passava por instigar os jovens a responderem a questões como: "Q ual a vossa opinião sobre estes resultados?" ou "Identificam-se com estes resultados?".

No que respeita à escolha dos participantes dos GDF, dada a índole sequencial do estudo, a prerrogativa central consistiu no facto de os jovens escolhidos 
terem feito parte da fase anterior da investigação. Efetivamente, existe uma relação nested (Onwuegbuzie e Collins, 2007) entre as duas amostras, uma vez que os intervenientes dos GDF constituem uma subamostra daqueles que haviam respondido ao inquérito por questionário.

Participaram nesta etapa 22 estudantes - maioritariamente do sexo feminino (77,3\%). Realizaram-se três GDF com estudantes do ensino regular (seis estudantes do $9 .^{\circ}$ ano; seis do $10 .^{\circ}$ ano; quatro do $12 .^{\circ}$ ano) e um GDF com seis estudantes do $11 .^{\circ}$ ano do ensino profissional. Importa referir que se considerou essencial que um dos grupos de jovens pertencesse ao ensino profissional, de forma a manter a diversidade da primeira etapa do estudo.

Tal como na fase quantitativa, foram recolhidos consentimentos informados (inclusive dos encarregados de educação) previamente à dinamização dos GDF, que decorreram na primeira quinzena do mês de março de 2020. Tendo por base os objetivos da investigação, procedeu-se a uma análise temática dos dados qualitativos (Braun e Clarke, 2006).

\section{A $\operatorname{tag}^{2}$ de análise de dados: do uso das RS como estratégia de parti- cipação ao seu papel no envolvimento político juvenil}

De modo a responder ao objetivo explicitado na secção metodológica, esta tag incorpora a articulação entre os resultados quantitativos e os qualitativos.

A partir de uma análise descritiva, e tendo em conta que as escalas variam entre 1 e 5, observa-se que, no que toca à escala da "participação cívica e política nas redes sociais online", estas plataformas emergem como um espaço onde os jovens tendem a participar $\left(\mathrm{M}_{\text {participaçãoRs }}=2.71\right.$, DP =1.05). As formas de participação com níveis mais altos são: "apoiar uma causa política, social ou ambiental através de um like ou comentário" e "visitar perfis de redes sociais com conteúdo relacionado com direitos humanos, LGBT ou ambientais". Relativamente ao interesse e à eficácia política, importa, em primeiro lugar, salientar que os jovens apresentam baixos níveis de interesse e de eficácia política interna $\left(\mathrm{M}_{\text {interesse }}=2.27, \mathrm{DP}=1.01 ; \mathrm{M}_{\text {eficácia interna }}=2.25, \mathrm{DP}=1.09\right)$, mas um nível elevado de eficácia política coletiva $\left(\mathrm{M}_{\text {eficácia coletiva }}=3.95, \mathrm{DP}=\right.$ .89). Ou seja, apesar de considerarem que os jovens, coletivamente, podem ter um papel relevante na melhoria das coisas, os inquiridos revelam pouco interesse na política e sentem que, individualmente, teriam pouco poder para influenciar a mudança social e política.

De modo a explorar como os jovens inquiridos se encontram agrupados

por perfis de envolvimento cívico e político nas RS, realizou-se uma análise múltipla de clusters. Utilizaram-se como variáveis as quatro dimensões que 
temos vindo a considerar: i) participação cívica e política nas redes sociais online; ii) interesse político; iii) eficácia política interna; iv) eficácia política coletiva. A solução de quatro clusters explica cerca de $52 \%$ da variância. Os resultados mostram um conjunto de quatro perfis ${ }^{3}$ (figura 1):

Figura 1. Perfis de envolvimento cívico e político nas RS

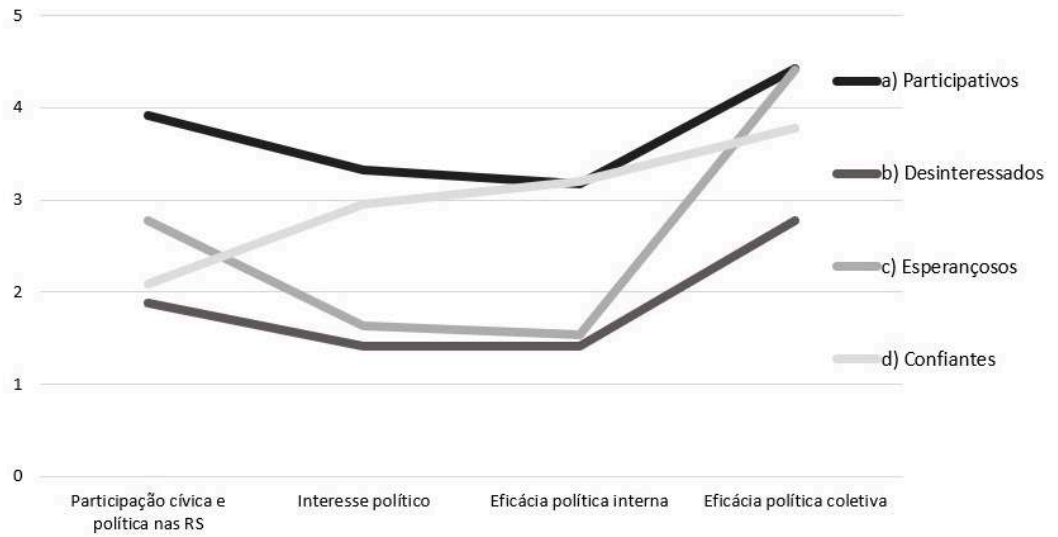

- a) Participativos [N=90]: os jovens que apresentam o nível maior de participação cívica e política nas RS; apresentam também índices consideráveis de interesse e de eficácia política (interna e coletiva); - b) Desinteressados [N=77]: aqueles que apresentam níveis reduzidos em todas as formas de participação; não se interessam, participam pouco e sentem que nem eles, nem os jovens, coletivamente, podem ter um papel relevante na mudança social e política;

- c) Esperançosos [N=134]: os inquiridos que acreditam que os outros jovens podem ter um papel relevante na melhoria das coisas; no entanto, revelam pouco interesse na política e sentem que, individualmente, teriam pouco poder para influenciar a mudança social e política; apresentam, concomitantemente, um nível mediano de participação nas RS;

- d) Confiantes $[\mathrm{N}=81]$ : os jovens que, apesar de participarem pouco, sentem que quer eles, quer os restantes jovens possuem um papel e poder na melhoria social e política.

Quando os participantes falam sobre a participação cívica e política nas redes sociais online, observam-se similaridades com os dados quantitativos. Joana ${ }^{4}$, uma estudante do $12 .^{\circ}$ ano do ensino regular, afirma: "olhando para

3 Neste ponto, sublinha-se que nas análises efetuadas, quer em testes de associação, quer em testes de diferenças, não foi possível verificar diferenças estatisticamente significativas entre estes perfis e as variáveis socioeconómicas.

4 Todos os nomes dos/as participantes são fictícios, de forma a preservar o seu anonimato. 
aqui, eu concordo que o que se poderá fazer mais é, sim, apoiar uma causa através de um like ou comentário". De facto, a partir dos GDF, é possível verificar que os jovens usam as RS para partilhar conteúdos que os preocupam, para influenciar outras pessoas e para condenar ou melhorar certos atos. Os participantes do $9 .^{\circ}$ ano falam sobre isto:

Moderador: Por exemplo, nas redes sociais já fizeram alguma coisa?

Rita: Ah sim, isso já. Já partilhámos alguma coisa.

Gonçalo: Sim, isso já.

Adriana: Isso já, sim.

Moderadora: Sim? Que tipo de coisas?

Gonçalo: Por exemplo, os incêndios na A ustrália.

Rita: O u uma imagem mais pesada para chamar as pessoas à razão.

Andreia: Para condenar certos atos.

Moderador: E fazem isso para demonstrar interesse, para fomentar o debate ou fazem porfazer, por verem outros a fazê-lo?

Andreia: Não. Eu meto aquilo como um a form a de alerta para as pessoas deixarem de fazer certas coisas ou para terem mais cuidado nas medidas que tomam ou com as coisas que fazem.

Sobre os motivos de participarem mais online, os estudantes do $9 .^{\circ}$ ano dizem que estas plataformas estão ao alcance de qualquer um e constituem uma forma mais fácil de participar.

Filipa: Se calhar porque está mais ao nosso alcance, é mais fácil repostarmos algum a coisa.

Rita: Exato. É mais fácil do que sair à rua, alguns pais não deixam fazer isso sozinhos e como estão a trabalhar complicam um bocado.

Moderador: Vocês disseram que era mais fácil, mas porquê? O que as redes sociais têm que facilita essa participação?

Rita: Porque toda a gente usa.

Filipa: E tem também um alcance muito maior e é muito mais fácil, basta carregar num botão e já está.

Joana, do $12 .^{\circ}$ ano, constata ainda que as RS podem ser um meio facilitador na comunicação quando se organizam ações políticas de maior dimensão e que estas plataformas "até podem ser uma primeira fase para depois se participar noutras formas ou assim". Outra participante, do 9..$^{\circ}$ ano, partilha a mesma opinião: "Sim [em referência ao papel das RS no fomento de outras ações de PCP], para continuar a lutar, por exemplo, para fazer manifestações e outras coisas". 
Relativamente às potencialidades na transição da PCP online para o offline, os jovens identificam, a montante, um estímulo e a promoção de possibilidades para o engajamento político offline - "por exemplo, vejo muitas vezes partilhas sobre manifestações que vão acontecer" [João, 11..$^{\circ}$ ano do ensino profissional] e "a maioria das associações consegue promover as suas causas através dos seus posts, e isso até pode influenciar um bocado" [Manuel, 11. "ano, do ensino profissional]. A jusante, as RS parecem representar um instrumento útil para seguir os acontecimentos sociais do dia a dia. Sara, uma estudante do 12. ' ano do ensino regular, fala sobre isto: "Eu acho que a maioria dos jovens começa pelas redes sociais a saber a inform ação, porque é o primeiro contacto que nós temos sobre as notícias em geral". Por último, é referido que as RS constituem também um veículo para práticas partidárias de recrutamento e mobilização da população juvenil.

Joana: Ao nível da política, a maioria dos partidos criaram contas nas redes sociais, por exemplo. Há dois ou três anos acho que não havia nada disso.

Moderador: Porque achas que isso aconteceu?

Joana: Eu acho que é para atrair e atingir as camadas jovens mais facilmente.

Rosa: Exatamente.

Joana: Eu acho que pensam assim: se calhar os jovens não leem tantos jornais e isso; então tentam arranjar um estratagem a para chegar a estas pessoas. E acho, por exemplo, o Twitter foi uma dessas formas. Cada vez mais estão a aderir e a publicar. Aliás, mesmo entre os políticos já há quem comente as publicações uns dos outros.

A partir das vozes juvenis, é possível apontar também tendências menos positivas. Os estudantes do $10 .^{\circ}$ ano do ensino regular alegam que existe uma discrepância entre o modo de participação nas RS e a transição para formas de participar offline. Ou seja, ocorre uma disparidade entre o que publicam e o que fazem nas suas práticas quotidianas.

Bárbara: Sei lá, faz-me alguma impressão ver as pessoas a publicarem coisas sobre as alterações climáticas e assim. Por exemplo, eu ando na natação e andam lá umas raparigas que se preocupam imenso e estão sempre a postar coisas no Instagram a dizer que temos que ajudar o mundo. Mas, por exemplo, chega ao balneário e fica uma hora no chuveiro a gastar água. E no dia anterior, se calhar pôs uma publicação a dizer para poupar a água, porque é super-importante. Eu acho que as pessoas publicam coisas só que não passam para a ação. 
Bruna: Eu acho que é para terem atenção e por estar na moda e não sabem muito bem do que estão a falar.

Guilherme: Na minha opinião, neste caso das histórias do Instagram, eu acho que as pessoas põem as fotos e os posts para dizerem que estão lá e, supostamente, preocupo-me com isto.

Bruna: Sim, para mostrarem que são boas pessoas.

Esta perspetiva é também expressa por Andreia, uma jovem do 9. ${ }^{\circ}$ ano do ensino regular - "Só que há pessoas que também metem só para dizer que se preocupam" - e por Sara, uma jovem do $100^{\circ}$ ano, que refere que as práticas nestas plataformas podem fazer com que as pessoas pensem que estão a ajudar, "sem ter de se mexer".

Apesar destas tomadas de posição, os participantes parecem revelar interesse e até posturas críticas sobre certos assuntos sociais e políticos. Observe-se, por exemplo, o diálogo entre estudantes do $10 .^{\circ}$ ano:

Bruna: Eu sigo uma página que é sobre feminismo e [que] mostra muitas notícias sobre o tema. E acho que estes tipos de páginas são importantes. Também sigo a Greta Thunberg e vejo fotos das manifestações a que ela vai e algumas informações sobre os problemas [por] que passamos atualmente.

Sara: A Time também posta muitas coisas sobre assuntos sociais e políticos.

Bruna: Também sigo a Emma Watson que também aborda muitas coisas sobre o feminismo.

Moderador: Mas seguem exatamente por ter interesse nas temáticas que as pessoas falam?

Bárbara: Sim, às vezes vemos um post, achamos interessante e começamos a seguir.

No que respeita à influência que as $\mathrm{RS}$ podem ter no envolvimento político juvenil, alguns participantes dos GDF referem que estas plataformas podem constituir uma ferramenta para fomentar o interesse e engajamento cívico dos jovens. De facto, relatam uma possível relação positiva entre o contacto com conteúdo social e político nas RS e o aumento do interesse nestas questões. Adriana, uma estudante do 9. ${ }^{\circ}$ ano, explora este efeito 'bola de neve':

Por exemplo, uma pessoa vê um determinado assunto num perfil e não acha importância e avança. E vai vendo em vários perfis e esse assunto vai aparecendo, aparecendo e a pessoa pode pensar que se calhar aquilo é importante e se interessa em saber o que se passa. E pode ler e procurar saber mais. 
Importa notar ainda que nos relatos é possível identificar alguns exemplos de RS como uma fonte de influência. Catarina, uma estudante do 12. ${ }^{\circ}$ ano, assume que a sua posição relativamente aos assuntos de carácter ambiental foi influenciada pelo que foi vendo nas redes sociais online - "acho que as redes sociais têm ajudado a aumentar esse apoio e essa preocupação [...]; no meu pensamento é algo que está mais presente do que antes".

\section{Logout: Conclusões do estudo}

Esta investigação procurou estudar as atitudes e comportamentos cívicos e políticos juvenis nas RS e compreender o papel que estas têm, ou podem ter, na participação dos jovens. Optou-se por um desenho de investigação composto por uma metodologia mista, de modo a possibilitar uma abordagem aprofundada e articulada dos fenómenos em estudo.

Foi possível agrupar os participantes em quatro perfis de envolvimento cívico e político nas RS: participativos - aqueles que apresentam índices consideráveis de PCP nas RS e de interesse e eficácia política; desinteressados - os participantes que apresentam níveis reduzidos em todas as formas de participação; esperançosos - os jovens que, apesar de terem pouco interesse na política, apresentam um nível mediano de participação online; e confiantes - aqueles que acreditam que quer eles, quer os outros jovens possuem um papel e poder na melhoria social e política.

Os resultados deste estudo parecem ilustrar a "reinvenção do ativismo político" (Norris, 2002) protagonizada pelos jovens. O meio online, neste caso as RS, emerge como um espaço onde os jovens tendem a participar ligeiramente mais (e.g., Hodgin, 2019; Mihailidis, 2014). De facto, ao contrário de algumas investigações (e.g., Livingstone, 2019) que reportam que é menos recorrente o uso da internet pelos jovens para se envolverem em assuntos 'sérios', os participantes deste estudo identificam algumas ações de participação cívica e política nas RS. Com efeito, e analogamente ao que referem outros autores, os jovens utilizam as RS como um instrumento para denunciar ou apoiar eventos políticos (e.g., Mihailidis, 2014), como fonte de informação sobre acontecimentos sociais (e.g., Cardoso, 2011) e, ainda, como um meio para influenciarem outras pessoas. Ao encontro do estudo de Campos et al. (2016), os discursos juvenis sublinham também o papel relevante que as RS podem ter na disseminação de atividades ou eventos sociais, na coordenação de ativistas em ações maiores, bem como no recrutamento e mobilização da população juvenil em partidos políticos.

Ademais, na linha de outros estudos (e.g., Loader et al., 2014; Valenzuela et al., 2009), os resultados desta investigação sublinham também a possível 
relação positiva entre o uso das RS e o aumento do envolvimento e compromisso cívico e político juvenil. Efetivamente, os discursos dos jovens indicam que a abundância de temas 'sérios' nestas plataformas pode aumentar a probabilidade de se interessarem por estas temáticas. Além disso, os resultados reforçam investigações anteriores (e.g., Kahne e Bowyer, 2019) que argumentam que as ações online podem estabelecer um estímulo para o engajamento offline.

Por outro lado, os participantes referem que alguns comportamentos cívicos e políticos nas RS se traduzem em slacktivism (e.g., Morozov, 2011), visto constituírem atividades que não correspondem a atitudes e comportamentos políticos fora da esfera online. Os jovens mencionam que algumas destas ações derivam da intenção de mostrar aos outros que são interessados, mas traduzindo-se depois em práticas pouco implicadas (Campos et al., 2016). Aqui, importa notar que esta asserção se aproxima do perfil de jovens 'esperançosos'. Ou seja, tendo em conta que estes jovens apresentam níveis medianos de participação nas RS e pouco interesse em assuntos sociais e políticos, pode deduzir-se um escasso grau de comprometimento das suas ações online.

No que concerne às atitudes políticas juvenis, os dados quantitativos mostram que os jovens inquiridos revelam pouco interesse na política e sentem que, individualmente, têm pouco poder para influenciar a mudança social e política (e.g., Magalhães e Moral, 2008). No entanto, consideram que, em conjunto, podem ter um papel relevante na melhoria das coisas. Relativamente aos dados dos GDF, estes indicam uma dupla perspetiva relativamente ao interesse e eficácia política juvenil. Por um lado, os jovens referem o desinteresse - mesmo na esfera online - relativamente a conteúdos sociais e políticos (e.g., Sander e Putnam, 2010). Por outro lado, observam-se comportamentos online assentes numa narrativa interessada e crítica sobre questões sociais (e.g., Malafaia et al., 2016). Por exemplo, o ato de seguir online temas sociais e políticos - um dos modos de participação relatados - alicerça-se na atenção e interesse por estas questões.

Em suma, este estudo contribui para o entendimento do papel das RS na reconfiguração do espetro de possibilidades de envolvimento político juvenil. Os resultados mostram que estas plataformas se configuram como um novo espaço de partilha e de ação para a mudança social, capaz de mobilizar a população mais jovem. Contribuindo para complexificar a ideia de que a população juvenil é desinteressada, este estudo mostra que a esfera online é um espaço onde os jovens mostram (e fomentam) interesse e informação sobre assuntos sociais e políticos, posicionando-se criticamente sobre eles. De facto, os perfis mostram que o envolvimento online se conjuga com atitudes cívicas e políticas (interesse e eficácia política) que são preditoras de comportamentos de participação que vão além da esfera online (e.g., Ekman e Amnå, 2012). Em segundo lugar, é interessante perceber, através do cruzamento entre o quantitativo e o 
qualitativo, que o envolvimento nas redes sociais tende a relacionar-se com formas mais expressivas e informais de participação. Causas políticas concretas (e.g., feminismo, clima), ligadas a movimentos sociais não institucionalizados, foram particularmente salientadas durante os grupos de discussão, sugerindo que estes movimentos são eficazes na comunicação online das suas mensagens. Em terceiro lugar, é interessante perceber a vigilância crítica quanto à tradução de algumas práticas digitais em slacktivism. Através das explorações quantitativas e qualitativas sobre os usos de RS, este estudo mostra que os perfis de participação nas RS não são dicotómicos, mas sim matizados por modos de envolvimento pré-políticos ou de standby (ilustrado pelo perfil confiante) e por relações emocionais com os conteúdos online (como emerge nos GDF). Concluindo, deste trabalho resultam pistas que favorecem o debate, a problematização e a análise crítica das atitudes e comportamentos cívicos e políticos online e do papel das RS no envolvimento dos jovens com a política.

Quanto às limitações do estudo, reconhece-se que o facto de a recolha de dados se ter circunscrito a uma escola impossibilitou uma amostra mais diversificada em termos socioeconómicos, que conferisse maior amplitude e variância nos perfis encontrados. Além disto, e tendo este artigo explorado os diferentes modos como os jovens se relacionam com as redes sociais - em termos de atitudes e comportamentos cívicos e políticos -, análises futuras deverão procurar examinar a implicação destes perfis nas práticas e sociabilidades juvenis.

\section{Referências bibliográficas}

BARRETT, Martyn, ZANI, Bruna (2015), Political and Civic Engagement. Multidisciplinary perspectives, London, Routledge.

BAUMGARTNER, Jody C., MORRIS, Jonathan S. (2009), "MyFaceTube Politics", Social Science Computer Review, 28 (1), 24-44.

BENEDICTO, Jorge (2013), “The political cultures of young people: an uncertain and unstable combinatorial logic", Journal of Youth Studies, 16 (6), 712-729.

BEN NETT, W. Lance (2008), Changing Citizenship in the Digital Age, Cambridge, The MIT Press.

BOYD, Danah (2008), "Why youth social network sites. The role of networked publics in teenage social life", in David Buckingham (org.), Youth, Identity, and Digital Media, Cambridge, The MIT Press, 119-142.

BRAUN, Virginia, CLARKE, Victoria (2006), "Using thematic analysis in psychology", $Q$ ualitative Research in Psychology, 3 (2), 77-101.

BUCKINGH AM, David (2008), Youth, Identity and Digital Media, Cambridge, The M IT Press.

CAMPOS, Ricardo, PEREIRA, Inês, SIMÕES, José Alberto (2016), “Activismo digital em Portugal: um estudo exploratório”, Sociologia, Problemas e Práticas, 82, 27-47.

CAMPOS, Ricardo, SIMÕES, José Alberto (2014), “Digital participation at the margins. Online circuits of rap music by Portuguese Afro-descendant youth”, Young, 22 (1), 87-106. 
CARDOSO, Gustavo (2011), “Mudança social em rede”, in Centro Ruth Cardoso (org.), Políticas sociais: ideias e prática, São Paulo, Editora Moderna LTDA, 219-258.

CARDoso, Gustavo, COSTA, António Firmino, COELHO, Ana Rita, PEREIRA, André (2015), A Sociedade em Rede em Portugal: um a década de transição, Lisboa, CIES-ISCTE.

CASTELLS, Manuel (2012), Redes de indignación y esperanza: los movimientos sociales en la era de Internet, Madrid, Alianza Editorial.

EKM AN, Joakim, AMNA, Erik (2012), "Political participation and civic engagement. Towards a new typology”, Human Affairs, 22 (3), 283-300.

EM LER, Nicholas P. (2011), "What does it take to be a political actor in a multicultural society?", in Martyn Barrett, Chris Flood, John Eade (org.), Nationalism, Ethnicity, Citizenship: Multidisciplinary perspectives, Newcastle, Cambridge Scholars, 135-161.

FARTHING, Rys (2010), “The politics of youthful antipolitics: representing the 'issue' of youth participation in politics", Journal of Youth Studies, 13 (2), 181-195.

HODGIN, Erica (2019), "Participatory politics and the civic dimensions of media literacy", in Renee Hobbs, Paul Mihailidis (org.), The International Encyclopedia of Media Literacy, New Jersey, Wiley-Blackwell, 1-11.

JEN KINS, Henry, CLINTON, Katie, PURUShotmA, Ravi, ROBISON, Alice, WEIGEL, Margaret (2009), Confronting the Challenges of Participatory Culture: Media education for the 21 st century, Chicago, The MacArthur Foundation.

KAHNE, Joseph, BOW YER, Benjamin (2019), "Can media literacy education increase digital engagement in politics?", Learning, Media and Technology, 44 (2), 211-224.

KAHNE, Joseph, MIDDAUGH, Ellen, ALLEN, Danielle (2015), "Youth, new media, and the rise of participatory politics", in Danielle Allen, Jennifer S. Light (org.), From Voice to Influence: Understanding digital citizenship in a digital age, Chicago, The University of Chicago Press, 33-55.

KOTILAINEN, Sirkku (2009), "Promoting youth civic participation with media production. The case of youth voice editorial board", AoC Unesco European Comission, 243-259.

LIVINGSTONE, Sonia (2011), "Internet, children and youth", in Mia Consalvo, Charles Ess (org.), The Handbook of the Internet Studies, Oxford, Blackwell, 348-368.

LIVINGSTONE, Sonia (2019), "EU Kids Online", in Renee Hobbs, Paul Mihailidis (org.), The International Encyclopedia of Media Literacy, New Jersey, Wiley-Blackwell, 1-17.

LOADER, Brian D., VROMEN, Ariadne, XENOS, Michael A. (2014), "The networked young citizen: social media, political participation and civic engagement", Information, Communication \& Society, 17 (2), 143-150.

LOPES, Joana, BENTON, Thomas, CLEAVER, Elizabeth (2009), "Young people's intended civic and political participation: does education matter?", Journal of Youth Studies, 12 (1), $1-20$.

LYONS, Evanthia (2008), Political Trust and Political Participation amongst Young People from Ethnic Minorities in the NIS and EU:A social psychological investigation. Final Report to INTAS, Belfast, Queen's University Belfast.

MAGAlhãeS, Pedro, MORAL, Jesus Sanz (2008), Os jovens e a política: Um estudo do Centro de Sondagens e Estudos de O pinião da Universidade Católica Portuguesa, Lisboa, Universidade Católica Portuguesa, CESOP.

M ALAFAIA, Carla, LUHTAKALLIO, Eeva, MENEZES, Isabel, NEVES, Tiago (2017), "Being civic while disavowing politics: An ethnography of a youth NGO in Portugal", Current Sociology, 66 (5), 769-787.

M ALAFAIA, Carla, MENEZES, Isabel, NEVES, Tiago (2016). "Os cidadãos continuam a ter direito à democracia: Discursos de jovens estudantes sobre as manifestações anti-austeridade em Portugal", Educação, Sociedade \& Culturas, 49, 51-71. 
MENEZES, Isabel, RIBEIRO, Norberto, FERNANDES-JESUS, Maria, MALAFAIA, Carla, FERREIRA, Pedro (2012), A gência e participação cívica e política: Jovens e Imigrantes na construção da Democracia, Porto, Livpsic/Legis Editora.

MIH AILIDIS, Paul (2014), Media Literacy and the Emerging Citizen. Youth, engagement and participation in digital culture, New York, Peter Lang.

MOROZOV, Evgeny (2011), The Net Delusion: the dark side of internet freedmon, New York, Public Affairs.

NIEM I, Richard G., CRAIG, Stephen C., M ATTEI, Franco (1991), "Measuring internal political efficacy in the 1988 National Election Study", The American Political Science Review, 85 (4), 1407-1413.

NORRIS, Pippa (2002), Democratic Phoenix. Reinventing political activism, Cambridge, Cambridge University Press.

ON W UEGBUZIE, Anthony J., COLLIN S, Kathleen M. T. (2007), “A typology of mixed methods sampling designs in social science research", The Q ualitative Report, 12 (2), 281-316.

PICKARD, Sarah (2019), Politics, Protest and Young People. Political participation and dissent in 21 st century Britain, London, Palgrave Macmillan.

PICKARD, Sarah, BESSAN T, Judith (2018), "Introduction”, in Sarah Pickard, Judith Bessant (org.), Young People Re-Generating Politics in Times of Crises, Basingstoke, Palgrave Macmillan, 1-16.

SAN DER, Thomas H., PUTNAM, Robert D. (2010), "Still bowling alone?. The post-9/11 split", Journal of Democracy, 21 (1), 9-16.

SIMÕES, José Alberto, CAMPOS, Ricardo (2016), "Digital media, subcultural activity and youth participation: the cases of protest rap and graffiti in Portugal", Journal of Youth Studies, 20 (1), 16-31.

SOEP, Elisabeth (2014), Participatory Politics: N ext-generation tactics to remake public spheres, Cambridge, The MIT Press.

VALENZUELA, Sebastián, PARK, Namsu, KEE, Kerk F. (2009), "Is there social capital in a social network site?. Facebook use and college students' life satisfaction, trust, and participation", Journal of Computer-Mediated Communication, 14 (4), 875-901.

VAN DETH, Jan (2014), “A conceptual map of political participation”, Acta Política, 49 (3), 349-367.

ZHANG, Weiwu, JOHnson, Thomas J., SElTZER, Trent, BICHARD, Shannon L. (2009), “The revolution will be networked", Social Science Computer Review, 28 (1), 75-92.

ZUCKERM AN, Ethan (2014), “New media, new civics?”, Policy \& Internet, 6 (2), 151-168.

- Receção: 13-11-2020

- Aprovação: 10-05-2021 